Cynthia D. Alexander MD, Bemard V. Wetchler MD, Robert E. Thompson MD PH D

\section{Bupivacaine infiltration of the mesosalpinx in ambulatory surgical laparoscopic tubal sterilization}

Pain following Yoon fallopian ring application for tubal sterilization is a cause of prolonged recovery time in the ambulatory surgery patient. ${ }^{1-3}$ Cramping and generalized pelvic pain may require significant amounts of narcotic analgesics. For the ambulatory surgical patient, sedation, nausea, vomiting and respiratory depression caused by narcotic analgesics may slow recovery and be responsible for an overnight admission to the hospital. ${ }^{4}$

Attempts to limit pain following tubal sterilization have included the use of narcotic analgesics intraoperatively; spraying or topical application of local anaesthetics onto the fallopian tubes; and injecting the fallopian tubes with a local anaesthetic agent when surgery was performed with local anaesthesia. ${ }^{5-9}$ More recently, etidocaine one per cent has been applied topically to the fallopian tubes prior to banding, resulting in a reduction of nausea, vomiting and need for postoperative narcotic analgesics. ${ }^{9}$

In this study the effects of mesosalpinx infiltration (beneath the area of fallopian ring application) with lidocaine one per cent, bupivacaine 0.5 per cent, or normal saline on reported pain intensity of patients in the postanaesthesia care unit (PACU) were compared to a control group who received no injection.

\section{Methods}

The study was approved by the Institutional Review Board of the Methodist Medical Center of Illinois. One hundred females of ASA physical status I or II, ranging in age from 21 to 40 , scheduled for elective laparoscopic sterilization with Yoon fallopian rings were chosen consecutively for the study and randomly assigned to one of four groups. Informed consent was obtained from all subjects.

Patients came to the ambulatory surgery centre two to seven days before their surgery for preanaesthetic evaluation and testing. At this time, the patients received an explanation of the self assessment pain intensity scale (Figure). This scale, which has been in use at The Methodist Medical Center of Illinois Pain Management Clinic for seven years, was adapted from the horizontal graphic rating sale. ${ }^{10}$ To enhance its sensitivity, key 


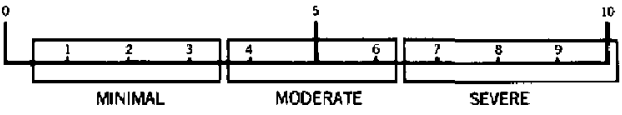

FIGURE Self-assessment pain intensity scale.

descriptive phrases were associated with the numbers on the scale. For example, a "10" on the scale was described as "pain as bad as it could be" while " 0 " was described as "no pain," with the mid-section labeled "moderate." Patients were instructed on the use of numerical responses to standard questions that would be asked of them regarding postoperative levels of pain associated with the area of the ring application (e.g., "deep pain"). These instructions were reinforced preoperatively by nursing personnel on the day of surgery. Even though different nurses interviewed the patients, all instructions and questions were standardized.

All study patients received premedication with atropine $0.3 \mathrm{mg}$ IM 30-45 minutes prior to surgery. Anaesthesia induction consisted of: d-tubocurarine $0.05 \mathrm{mg} \cdot \mathrm{kg}^{-1}$, thiopentone $4-5 \mathrm{mg} \cdot \mathrm{kg}^{-1}$, fentanyl $1.5 \mu \mathrm{g} \cdot \mathrm{kg}^{-1}$, succinylcholine $1 \mathrm{mg} \cdot \mathrm{kg}^{-1}$ and droperidol $0.009 \mathrm{mg} \cdot \mathrm{kg}^{-1}$. Following tracheal intubation, anaesthesia was maintained with nitrous oxide and oxygen $\left(3: 2 \mathrm{~L} \cdot \mathrm{min}^{-1}\right)$ and isoflurane. A succinylcholine drip ( 0.2 per cent) provided muscle relaxation as needed throughout the procedure.

The surgical technique consisted of insertion of a Veres needle and insufflation of the peritoneal cavity with carbon dioxide, followed by insertion of a trocar and laparoscopic application of Yoon fallopian rings. Following fallopian ring application, a 20-gauge spinal needle was inserted suprapubically through the skin into the peritoneal cavity. Under direct vision, the mesosalpinx distal to the area of the ring placement was infiltrated (2.5 $\mathrm{ml}$ per side) with either lidocaine one per cent (Group I), bupivacaine 0.5 per cent (Group II), or normal saline (Group III), Solutions were unknown to the gynaecologist, anaesthetist and operating room nurses. Controls (Group IV) received no infiltration. Following completion of surgery and anaesthesia, patients were taken to the PACU for monitoring of vital signs and pain levels. The patients" infiltration medication group was not known by the PACU staff.

Patients were questioned regarding their pain level by the PACU nurse at four times. Time one was 15 minutes after scoring ten on their Aldrete postanaesthesia recovery score (APARS); ${ }^{11}$ time two was just prior to ambulation; time three was just prior to discharge; and time four was at nine a.m. the morning following surgery. Pain levels were reported by patients based on the self-assessment pain intensity scule with scores from 0 to 10 as previcusly
TABLE I Pain intensity scores at time one, 15 minutes after scoring 10 on APARS

\begin{tabular}{lll}
\hline Group & Mean & SE \\
\hline Lidocaine*† & 4.6 & 0.4 \\
Bupivacaine* & 3.1 & 0.5 \\
Saline* $\dagger$ & 5.4 & 0.5 \\
Control $\dagger$ & 5.0 & 0.7
\end{tabular}

*Difference between treatments was stalistically significanı by Kruskall-Wallis $\mathrm{H}$ test, $\mathrm{p}<0.025$.

†Different from bupivacaine by Wilcoxen's Rank-Sum Test, $\mathrm{p}<0.05$.

discussed. After the first measurement of pain intensity, fentanyl $12.5 \mu \mathrm{g}$ was administered IV every five minutes by the PACU nurse for pain requiring analgesic medication. The fentanyl dose was not to exceed $50 \mu \mathrm{g}$ in the postanaesthesia recovery period without evaluation by the anaesthetist. Upon discharge from the facility patients were given tablets of acetaminophen with $30 \mathrm{mg}$ codeine to be taken at home, as needed for pain.

Comparison of the means for pain intensity of the four groups were done by the Kruskall-Wallis H-Test; pairwise comparisons were done by Wilcoxen's Rank-Sum Test for two independent samples. One-way analysis of variance (ANOVA) and Duncan's Multiple-Range Test were used to interpret pain medication data. Results for al] tests were considered significant at $p<0.05$.

\section{Results}

The four groups of study subjects were comparable in age (21-40), weight (48-86 kg) and general health (ASA physical status I or II). No side effects of the drugs were reported.

Patients who received bupivacaine 0.5 per cent (Group II) reported lower levels of pain intensity at all study times (Tables I-IV). Analysis of responses to the self-assessment pain intensity scale using the Kruskatl-Wallis $\mathrm{H}$ Test indicated the difference among groups was statistically significant $(p<0.05$ ) only at study time one. From these results, it can be concluded that bupivacaine 0.5 per cent provided greater pain relief, based on responses to the self-assessment pain intensity scale, than the other treatments, but only at 15 minutes after the patients scored ten on the APARS.

TABLE II Pain intensity scores at time two, just prior to ambulation

\begin{tabular}{lll}
\hline Group & Mean & $S E$ \\
\hline Lidocaine* & 4.6 & 0.4 \\
Bupivacaine & 3.5 & 0.4 \\
Saline & 4.2 & 0.5 \\
Control & 5.0 & 0.6 \\
\hline
\end{tabular}

*Different from bupivacaine by Wilcoxen's Rank-Sum test, $\mathrm{p}<0.05$. 
TABLE III Pain intensity scores at time three, just prior to discharge

\begin{tabular}{lll}
\hline Group & Mean & $S E$ \\
\hline Lidocaine & 4.0 & 0.3 \\
Bupivacaine & 3.0 & 0.4 \\
Saline & 4.2 & 0.5 \\
Control & 4.1 & 0.6 \\
\hline
\end{tabular}

$\mathrm{p}=\mathrm{NS}$.

A pairwise comparison of groups by Wilcoxen's Rank-Sum test provides additional insights into the clinical implications of the groups. This test supports the superior results for bupivacaine 0.5 per cent at study time 1 ( $p<0.05)$. The bupivacaine group had significantly less reported pain when compared to every other group. At study time two, Wilcoxen's Rank-Sum Test indicates that reported pain intensity was significantly lower for the bupivacaine 0.5 per cent group than the lidocaine group $(p<0.05)$. Wilcoxen's Rank-Sum test results showed no statistically significant difference between pairs of groups at study points threc and four.

Patients who received bupivacaine 0.5 per cent required significantly less fentanyl supplementation in the postoperative period (mean $4.9 \mu \mathrm{g} ;$ SE 3.0) than all other groups. Based on the patients' requests for and the amount of analgesics received postoperatively, the bupivacaine 0.5 per cent treatment offered greater pain relief $(\mathrm{p}<0.05)$.

\section{Discussion}

To accept the conclusion that bupivacaine 0.5 per cent provides greater pain relief than lidocaine, saline or no infiltration, two assumptions must be made. First, the effects of drugs given during anaesthesia were the same or similar for all patients. Secondly, the drugs given during anaesthesia did not confound the effects of the bupivacaine, lidocaine or normal saline. These assumptions are reasonable since no interactions among the drugs given during anaesthesia and the test group drugs are documented. ${ }^{12}$ Because of the short duration of low-dose fentany $l^{13}$ given during anaesthetic induction, the analgesic effects probably did not play a major role in pain relief after the paticnts reached the first measurcment time.

TABLE IV Pain intensity scores at time four, 9 a.m. the day after surgery

\begin{tabular}{lll}
\hline Group & Mean & $S E$ \\
\hline Lidocaine & 2.5 & 0.4 \\
Bupivacaine & 1.8 & 0.4 \\
Saline & 2.4 & 0.4 \\
Control & 2.1 & 0.6 \\
\hline
\end{tabular}

$p=$ NS.
TABLE V Fentanyl dose $(\mu \mathrm{g})$ in the PACU

\begin{tabular}{lrl}
\hline Group & Mean & $S E$ \\
\hline Licodaine* $^{*}$ & 9.1 & 4.0 \\
Bupivacaine* & 4.9 & 3.0 \\
Saline* & 28.7 & 5.8 \\
Control*† & 30.7 & 7.0 \\
\hline
\end{tabular}

*Difference between doses statistically significant by ANOVA, $p<0.05$. -Different from bupivacaine by Duncan's Multiple-Range test, $p<0.05$. $\doteqdot$ Different from lidocaine by Duncan's Multiple-Range test, $\mathrm{p}<0.05$.

(Usual duration of analgesic action after a single IV dose of fentanyl up to $100 \mu \mathrm{g}$ is $30-60$ minutes. $)^{13}$ The length of time between the initial fentanyl dose during anaesthesia induction and the initial measurement of pain intensity was not less than 45 minutes for all cases.

After the first pain intensity measurement, fentanyl $(12.5 \mu \mathrm{g})$ was given to patients every five minutes as needed by the patient for pain. The analgesic effect of this drug would cause patients to report lower levels of pain than if they had received no postoperative medicine Although it is known how much fentanyl each group received, it is not known when it was given. Documentation of fentanyl administration times might indicate when patients in each group had the highest pain intersity. The effects of fentanyl on pain intensity may explain why the saline group had less pain than the lidocaine group at time two and the control group had less pain than the saline group at time three.

To further document the effects of bupivacaine $0.5 \mathrm{per}$ cent on pain relief in Yoon fallopian ring application, replications of this study should be done. The amount of fentanyl given during each measurement interval should be documented so that additional inferences about levels of pain can be made.

Although different nurses interviewed the patients, observer and respondent bias should have been kept at a minimum due to the standardization instrument, the type of scale used for this study provides the best method for measuring pain or pain relief. ${ }^{10}$

This initial study indicates bupivacaine 0.5 per cent is the preferred drug for infiltation of the mesosalpinx for pain relief following Yoon ring application of the fallopian tube.

\section{Acknowledgements}

The authors wish to thank Cheryl M. Fliege, M.A., for her help in the preparation of the manuscript and Warren E. McReynolds, Ph.D., Bradley University for his assistance with the statistical analysis. 


\section{References}

$1 H_{\text {crlka }} \mathrm{J}$, Interest in reversibility stimulates success of Hulka clip. Same-Day Surgery 1980; 4: 84-5.

2 Yoon $F$. Falope ring offers safety, limited tubal damage. Same-Day Surgery 1980; 4: 85-6.

3 Burntill MS. Pitfalls of the falope ring. Same-Day Surgery $1980 ; 4: 86-8$.

4 Fishburne Jl. Office laparoscopic sterilization with local anaesthesia. The Journal of Reproductive Medicine 1977 18: $233-4$.

5 Fishburne JI, Omran K, Hulka JF, Mercer JP, Edelman $D A$. Laparoscopic tubal clip sterilization under local anaesthesia. Fertility and Sterility $1974 ; 25: 762-6$.

6 Mercer JP, Hulka JF, Fishburne JI, Kumarasamy T, Omran $K F$. Spring clip tubal sterilication. Obstet Gynecol 1974; 44: 449-54.

7 Pelland PC. The application of lidocaine to the fallopian tubes during tubal fulguration by laparoscopy. Obstet Gynecol 1976; 47: 501-2.

8 Koetsawang S, Srisupandit S, Apimas SI, Champion C. A comparative study of topical anesthesia for laparosecpic sterilization with use of the tubal ring. Am J Obstet Gynecol 1984; 150: 931-3.

9 McKenzie R. Kennedy: RL. Chalasani J, Phitayakirb O Melnick B, Virinie III BS. Etidocaine for pain relief after laparoscopic tubal occlusion under general anesthesia. Anesthesiology 1984; 61: A230.

10 Scort $J$, Huskisson EC. Graphic representation of pain. Pain 1976; 2: 175-84.

11 Aldrete $J A$, Kroulik $D$. A postanesthetic recovery score. Ancsth Analg 1970; 49: 924-34.

12 Mangini RJ, Blaschke RJ, Cohen SN, Tarros DS. Drug intcraction facts. 1986 updated edition. St. Louis: J. B. Lippincott Company, 1984: 89, 407

13 MCEvoy $G K$ (Ed.) Drug information 1986. Bethesda, Maryland: American Society of Hospital Pharmacists: 1986: 905.

\section{Résumé}

On a comparé l'infiltration de bupivacaine dons le mésosalpinx, à celle de la lidocaïnc, du salin nornal ou à atcune injection pour le soulagement de la douleur chez des femmes subissant une laparoscopie élective pour stérilisation tubaire par anneaux de trompes de Yoon. Ort a réparti de façon aléasoire, 100 femmes en quatre groupes. Dans une énude da double insu, on a infilirele mésosalpinx dans trois groupes: Groupe I - 1.0 pour cent de lidocaine; Group II - 0.5 pour cent de bupivacaine; Groupe III - salin normal. Le groupe IV (groupe-témoin) r'a pas reçu d'injection. Les patients ont rapporté l' intensité de leur douleur à quatre moments dans l'étude, en faisant une évaluation personnelle sur une échelle d'intensité de la douleur. On a comparé les réponses en utilisant le tesi $H$ Kruskall-Wallis et le test de sanme des rangs de Wilcoxen. Les dew tests démun. traient des différences significatives dans les niveaux d'intensité de la douleur, à différents moments de l'étude. La quantilé de fentanyl supplémentaire donnêe a êtê utilisée comme mesure secondaire de l'efficacité. Une analyse de variance unidirectionnelle (ANOVA) et le test à ecarts multiples de Duncan ont démontré que le groupe bupivacaine recevait significalivement moins de fentanyl $(p<0.05$ ) dans l'wité des soins postanesthésiques. 